\title{
SOLVENT EFFECT ON THE STRUCTURAL, ELECTRONIC, SPECTRA PROPERTIES AND FIRST HYPERPOLARIZABILITY OF W(CO) 5 , L=(4-PYRIDYLMETHYLENE)MALONONITRILE
}

\author{
REZA GHIASI*,1, MAHDIYEH NEMATI ${ }^{1}$, AMIR HOSSEIN HAKIMIOUN® ${ }^{2}$ \\ ${ }^{1}$ Department of Chemistry, East Tehran Branch, Qiam Dasht, Tehran, Islamic Azad University, IRAN \\ ${ }^{2}$ Young Researchers and Elites club, North Tehran Branch, Islamic Azad University, Tehran, IRAN
}

\begin{abstract}
In this work, the structural, electronic properties, ${ }^{14} \mathrm{~N}$ NQR parameters and first hyperpolarizability of $\mathrm{W}(\mathrm{CO})_{5} \mathrm{~L}, \mathrm{~L}=(4$-pyridylmethylene)malononitrile complex were computed in gas phase by hybrid functional PBE method with LanL2DZ, and 6-311G(d,p) basis sets for transition metal and man group elements, respectively. Also, the solvent effect on structural parameters, frontier orbital energies of complexes has been carried out based on Polarizable Continuum Model (PCM). The results indicate that the polarity of solvents has played a significant role on the structures and properties of complex. ${ }^{1} \mathrm{H}$ and ${ }^{13} \mathrm{C}$ NMR chemical shifts were calculated by using the Gauge-invariant atomic orbital (GIAO) method. By analyzing the structural characteristics of this structure, W-C and W-N bonds were identified and characterized in details by topological parameters such as electron density $\rho(r)$ and Laplacian of electron density $2 \circledR \nabla^{2} \rho(r)$ from Bader's atom in molecules theory.
\end{abstract}

Keywords: $\mathrm{W}(\mathrm{CO})_{5}$-pyridine- $\pi$-acceptor complex, ${ }^{14} \mathrm{~N}$ NQR parameters, Frontier orbitals analysis, solvent effect, NBO analysis, QTAIM analysis.

\section{INTRODUCTION}

The chemistry of the $\mathrm{M}(\mathrm{CO})_{5} \mathrm{~L}$ transition metal complexes has been comprehensively surveyed for the reason that of exclusive properties of the compounds belonging to the organometallic species. Since pyridine and its derivatives are utilized in many chemical structures of biomedical and industrial fields they have been investigated widespread [1-5]. Many theoretical and experimental researches have been reported for these complexes [6-8].

The $\mathrm{W}(\mathrm{CO})_{5} \mathrm{~L}(\mathrm{~L}=\mathrm{a}$ substituted pyridine) system is of individual importance because these complexes were the first 6 metal carbonyls observed to luminescence in frozen glasses [9-12] and in fluid [13,14]. Linear and secondorder non-linear optical $(\mathrm{NLO})$ properties of $\mathrm{W}(\mathrm{CO})_{5} \mathrm{~L}$ complexes (where $\mathrm{L}$ is pyridine or its 4 -substituted derivative) have been explored systematically [15-23]. The synthesis, structure and electronic absorption spectra of $\mathrm{W}(\mathrm{CO})_{5}-$ pyridine- $\pi$-acceptor complexes have been studied [24].

Solvent shows a considerable role in physical and chemical processes. The specific and non-specific interaction between the solvents and the solute molecules changes several properties similar to molecular geometry, electronic structure and dipolar moment of the solute [25-30].

This paper reports a computational study of $\mathrm{W}(\mathrm{CO})_{5} \mathrm{~L}, \quad \mathrm{~L}=(4$ pyridylmethylene)malononitrile complex. The structural, electronic, spectra properties and first hyperpolarizability of this complex in solution and gas phases have been explored theoretically.

\section{Computational method}

All calculations were carried out with the Gaussian 09 suite of program [31]. The calculations of systems containing of main group elements described by the standard 6-311G(d,p) basis set [32-35]. For tungsten element standard LANL2DZ basis set is used [36-38]. Tungsten described by the effective core potential (ECP) of Wadt and Hay pseudopotential [36] with a double-x valance using the LANL2DZ. Geometry optimization was performed utilizing the hybrid functional PBEPBE method [39]. A vibrational analysis was performed at each stationary point found, that confirmed its identity as an energy minimum.

For the study of solvation effects, we have used a self-consistent reaction field (SCRF) approach, using the polarizable continuum model (PCM) in particular [40]. Using this method, the geometry of the studied complex was re-optimized and the UV/Vis spectrum was calculated by DFT/TD-DFT with the same functionals and basis sets.

The population analysis has also been performed by the natural bond orbital method [41] using NBO program [42] under Gaussian 2009 program package.

The information of the MOs was evaluated by total, partial and overlap population density of states (DOS) using the GaussSum 3.0 [43].

The ionization potential (IP) and electron affinity (EA) can be either for vertical excitations ( $\mathrm{v}$, at the geometry of the neutral molecule) or adiabatic excitations (a, optimized structure for both the neutral and charged molecule).

The $\lambda_{\text {electron }}$ is electron reorganization energy, which can be expressed as follows: $\lambda_{\text {electron }}=\mathrm{EEP}-\mathrm{EA}(\mathrm{v})$

equation 1

EEP (electron Extraction potential) is the energy difference from $\mathrm{E}^{-} \mathrm{E}^{-}$ (anionic), using $\mathrm{E}^{-}$geometric structure in the calculation.

Likewise, $\lambda_{\text {hole }}$ for hole transfer can be expressed as follows:

$\lambda_{\text {hole }}=\mathrm{IP}(\mathrm{v})-\mathrm{HEP}$

equation 2

HEP (hole Extraction potential) is the energy difference from $\mathrm{E}$ (neutral molecule) to $\mathrm{E}^{+}$(cationic), with using $\mathrm{E}^{+}$geometric structure in the calculation

The AIM2000 program[44] was used for topological analysis of electron density and calculation of delocalization index. The following characteristics of ring critical points (RCPs) were taken into account: density at RCP $(\rho(\mathrm{rc}))$, and its Laplacian $\left(\nabla^{2}(\mathrm{r})\right)$.

The total static first hyperpolarizability $\beta$ was obtained from the relation:

$$
\beta_{\text {tot }}=\sqrt{\beta_{x}^{2}+\beta_{y}^{2}+\beta_{z}^{2}}
$$

equation 3

upon calculating the individual static components

$$
\beta_{i}=\beta_{i i i}+\frac{1}{3} \sum_{i \neq j}\left(\beta_{i j j}+\beta_{j i j}+\beta_{j j i}\right)
$$

equation 4

Due to the Kleinman symmetry [45]:

$\beta_{x y y}=\beta_{y x y}=\beta_{y y x} ; \beta_{y y z}=\beta_{y z y}=\beta_{z y y}, \cdots$

one finally obtains the equation that has been employed:

$$
\beta_{t o t}=\sqrt{\left(\beta_{x x x}+\beta_{x y y}+\beta_{x z z}\right)^{2}+\left(\beta_{y y y}+\beta_{y z z}+\beta_{y x x}\right)^{2}+\left(\beta_{z z z}+\beta_{z x x}+\beta_{z y y}\right)^{2}}
$$
equation 5

The electrostatic interaction of a nuclear electric quadrupole moment and the electron charge cloud surrounding the nucleus can give rise to the observation of pure Nuclear Quadrupole Resonance (NQR) [46]. The Hamiltonian of this interaction for a nucleus of spin I is given [47]:

$$
H_{Q}=\frac{e^{2} Q q_{z Z}}{4 I(2 I-1)}\left[3 I_{z}^{2}-I^{2}+\frac{\eta}{2}\left(I_{+}^{2}+I_{-}^{2}\right)\right] ; \quad \text { equation } 6
$$

where all values of I in the denominator are scalar values while all I' $\mathrm{s}$ in the square brackets are operators [48]. Quantum chemical calculations yield principal components of the EFG tensor, $\mathrm{q}_{\mathrm{i}, \mathrm{i}}$, in atomic units $(1 \mathrm{au}=9.717365 \times$ $10^{2} 1 \mathrm{Vm}^{-2}$ [8], with $\left|\mathrm{q}_{\mathrm{zz}}\right| \geq\left|\mathrm{q}_{\mathrm{yy}}\right| \geq\left|\mathrm{q}_{\mathrm{xx}}\right| \cdot \mathrm{q}_{\mathrm{xx}}, \mathrm{q}_{\mathrm{yy}}$ and $\mathrm{q}_{\mathrm{zz}}$ are the components of EFG in the directions of $x, y$ and $z$, respectively. The calculated $q_{i j}$ values were used to obtain the nuclear quadrupole coupling constants, $\chi_{\mathrm{ii}}$ :

$$
\chi_{i i}(M H z)=\frac{e^{2} Q q_{i i}}{h} i=x, y, z ; \quad \text { equation } 7
$$


where $\mathrm{Q}$ is the nuclear quadrupole moment of the ${ }^{14} \mathrm{~N}$ nucleus. The standard values of quadrupole moment, Q, reported by Pyykkö [49] were used in Eq. (1), $Q\left({ }^{14} \mathrm{~N}\right)=20.44 \mathrm{mb}$. Often the NQR parameters are reported as the nuclear quadrupole coupling constant experimentally, and have the unit of frequency:

$$
Q C C=\chi(M H z)=\frac{e^{2} Q q_{z Z}}{h} ; \quad \text { equation } 8
$$

Asymmetry parameters $\left(\eta_{Q}\right)$ are defined as:

$$
; \quad \eta_{Q}=\left|\frac{\left(q_{y y}-q_{x x}\right)}{q_{z z}}\right| ; 0 \leq \eta_{Q} \leq 1 ; \quad \text { equation } 9
$$

since it measures the deviation of the field gradient tensor from axial symmetry.

For a nucleus of unit spin ( $\operatorname{such}$ as ${ }^{14} \mathrm{~N}$ ), we have three energy levels, so we get three nuclear quadrupole resonance frequencies [47]:

$$
\begin{aligned}
& v_{+}=\frac{3}{4} \chi_{z z}\left(1+\frac{\eta}{3}\right) \quad \text { equation } 10 \\
& v_{-}=\frac{3}{4} \chi_{z z}\left(1-\frac{\eta}{3}\right) \quad \text { equation } 11 \\
& v_{0}=\frac{3}{4} \chi_{z z} \eta \quad \text { equation } 12
\end{aligned}
$$

The quadrupole coupling constant $\left(\chi_{z z}\right)$ and asymmetry parameter $(\eta)$ are usually calculated from the nuclear quadrupole frequencies as follows:

$$
\begin{array}{lll}
; & \chi_{z z}=\frac{2\left(v_{+}+v_{-}\right)}{3} ; & \text { equation } 13 \\
; & \eta=\frac{3\left(v_{+}-v_{-}\right)}{\left(v_{+}+v_{-}\right)} ; & \text {equation } 14
\end{array}
$$

Chemical shift values are calculated using the Gauge independent atomic orbital (GIAO) [50] method at the same method and basis sets for optimization. GIAO method calculating nuclear magnetic shielding tensors is one of the most known approaches.

\section{RESULTS AND DISCUSSION}

\section{Energetic aspects:}

Figure 1 presents the structures and numbering schemes of atoms in the studied $\mathrm{W}(\mathrm{CO})_{5}$-pyridine- $\pi$-acceptor complex. The energies of the complex in gas phase and in different media by using the PCM model are listed in Table 1. From Table 1, we can see that the calculated energy is dependent on the size of the dielectric constant of solvents. In the PCM model, the energies E decrease with the increasing of dielectric constants of solvents. On the other hand, $\mathrm{E}_{\text {solv }}$ values indicate to increase stability in more polar solvents $\left(\mathrm{E}_{\text {solv }}\right.$ $\left.=-0.282 \varepsilon-5.904 ; R^{2}=0.957\right)$. This is because a dipole in the molecule will induce dipole in medium, and the electric field applied to the solute by the solvent (reaction) dipole will in turn interact with the molecular dipole, leading to net stabilization. This suggests that the complex has more stability in polar solvent rather than in the gas phase.

Table 1. Absolute energy (Hartree), salvation energy ( $\mathrm{kcal} / \mathrm{mol}$ ), Dipole moments (in Debye), Isotropic and anisotropic polarizability (in Bohr ${ }^{3}$ ) and dielectric constants of solvents for $\mathrm{W}(\mathrm{CO})_{5} \mathrm{~L}, \mathrm{~L}=(4$-pyridylmethylene)malononitrile in vacuum and various solvents.

\begin{tabular}{|c|c|c|c|c|c|c|}
\hline phase & $\varepsilon$ & $\mathbf{E}$ & $\mathbf{E}_{\text {solv }}$ & $\mu$ & $\alpha_{\text {iso }}$ & $\alpha_{\text {aniso }}$ \\
\hline Gas & - & -1143.8787 & - & 2.98 & 356.61 & 400.20 \\
\hline chloroform & 4.71 & -1143.8899 & -7.06 & 3.87 & 429.08 & 493.75 \\
\hline chlorobenzene & 5.70 & -1143.8908 & -7.57 & 3.96 & 435.61 & 496.63 \\
\hline THF & 7.43 & -1143.8917 & -8.16 & 4.07 & 443.31 & 499.22 \\
\hline methylenechloride & 8.93 & -1143.8923 & -8.51 & 4.13 & 447.66 & 500.06 \\
\hline quinoline & 9.16 & -1143.8923 & -8.55 & 4.13 & 448.21 & 500.11 \\
\hline isoquinoline & 11.00 & -1143.8928 & -8.84 & 4.19 & 451.88 & 500.57 \\
\hline
\end{tabular}

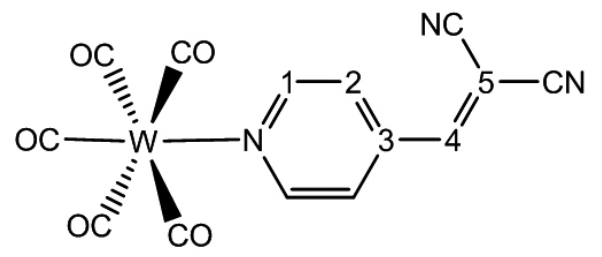

Figure 1. The structure of $\mathrm{W}(\mathrm{CO})_{5} \mathrm{~L}, \mathrm{~L}=(4$-pyridylmethylene) malononitrile complex.

\section{IPs and EAs}

The ionization potential (IP) and electron affinity (EA) are well-defined properties that can be calculated by DFT to estimate in the compounds. These values aim to get an in detail rationalization of the relationship between the structure and the electronic behavior of the molecule, in particular the response of the molecule to the formation of a hole, or to the addition of an electron, additional information is derived. IPs, EAs, both vertical and adiabatic, and the extraction potentials values (HEP and EEP for the hole and electron, respectively) that refer to the geometry of the ions have been calculated [51,52]. It can be found, the IP in molecule is $7.81 \mathrm{eV}$ and the value of $\mathrm{IP}_{v}$ is $7.70 \mathrm{eV}$. On the other hand, the EA value is $2.70 \mathrm{eV}$. And the EA for molecule is $2.80 \mathrm{eV}$.

The mobility of charges has been established to be related mainly to the internal reorganization energy $\lambda_{\text {hole electron. }}$. It can be found; the $\lambda_{\text {tole }}$ and $\lambda_{\text {electron }}$ values are 7.53 and $2.59 \mathrm{eV}$, respectively. The comparison of these values show that the $\lambda_{\text {hole }}$ values for molecule is more than its corresponding $\lambda_{\text {electron }}$ values, which indicates that the electron transfer rate is higher than the hole transfer rate.

\section{Dipole moments.}

Dipole moment values of $\mathrm{W}(\mathrm{CO})_{5}$-pyridine- $\pi$-acceptor complex in gas phase and in different media by using the PCM model are listed in Table 1. These values show the solvent effect on the stabilization energy is in parallel with that on the dipole moment of the solute. There is a good linear relationship between the solvent stabilization energies and the dipole moments molecule in the set of solvents with the correlation coefficient is $0.958(\mu=0.05 \varepsilon+3.665)$.

Namely, there is the larger the dipole moment of solute, and the higher the stabilization energy in the stronger the solvent polarity. Also, there is a good correlation between dipole moment and dielectric constant with the correlation coefficient is 0.958 .

\section{4. isotropic and anisotropic polarizability}

The isotropic and anisotropic polarizability values of the complex in gas phase and in different media by using the PCM model are listed in Table 1. These values show that the isotropic and anisotropic polarizability values increase with the increasing of dielectric constants of solvents (Figure 2). In addition, the polarizabilities are also noted to increase as the dielectric constant of the solvent is decreased. The dipole moments of the molecules are also noted to follow the same trend as their polarizabilities.

\section{Structural parameters}

The selected bond distances of $\mathrm{W}(\mathrm{CO})_{5}$-pyridine- $\pi$-acceptor complex are collected in Table 2. It is well-known that the solvent polarity influences both the structure and properties of conjugated organic molecules and metal complexes [53-55]. The structural data for the optimized structures of W(CO) pyridine- $\pi$-acceptor complex in six studied solvents are gathered in Table 2. 
The results show that the structural parameters are changed by the polarity of the surrounding media. These values indicate lengthening of $\mathrm{W}-\mathrm{C}_{\text {trans }}, \mathrm{W}-\mathrm{C}_{\mathrm{cis}}$, and shortening of W-N bonds in the set of solvents rather than gas phase. On the other hand, there are shortening of $\mathrm{W}_{-} \mathrm{C}_{\text {trans }}, \mathrm{W}-\mathrm{C}_{\text {cis }}$, and lengthen of $\mathrm{W}-\mathrm{N}$ bonds with increasing of polarity of solvents.

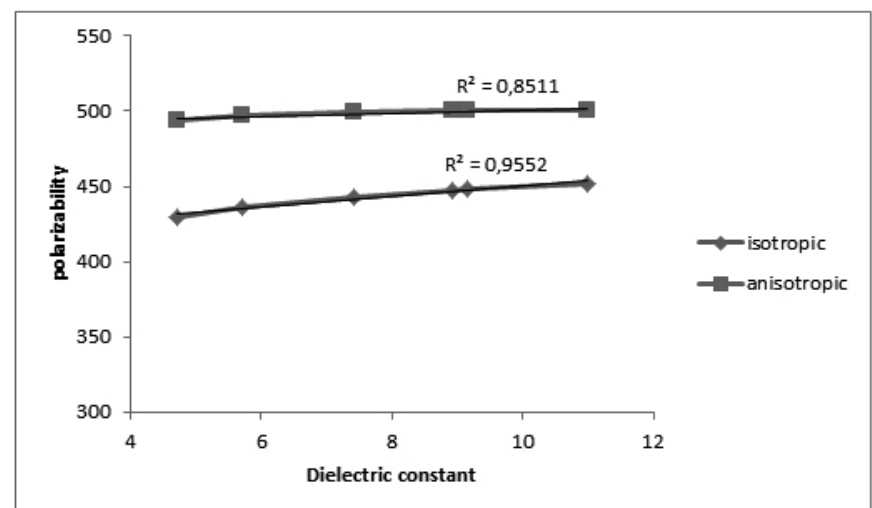

Figure 2. The linear correlation between polarizability and dielectric constants for $\mathrm{W}(\mathrm{CO}) 5 \mathrm{~L}, \mathrm{~L}=(4-$ pyridylmethylene)malononitrile complex.

Although theoretical results are not exactly close to the experimental values [56] for the title molecule, this may be due to the fact that the theoretical calculations were aimed at the isolated molecule in gaseous phase and the experimental results were aimed at the molecule in the solid state. The calculated geometric parameters also represent good approximation and they can be used as foundation to calculate the other parameters for the compound.

Table 2. Selected bond distances (in $\AA$ ) for $\mathrm{W}(\mathrm{CO})_{5} \mathrm{~L}, \mathrm{~L}=(4-$ pyridylmethylene)malononitrile in vacuum and various solvents.

\begin{tabular}{|c|c|c|c|}
\hline phase & W-N & $<\mathbf{W}_{\text {cis }} \mathbf{C}_{\text {e }}$ & $\mathbf{W}_{-C_{\text {trans }}}$ \\
\hline Exp* & 2.275 & 2.044 & 1.989 \\
\hline Gas & 2.260 & 2.052 & 2.007 \\
\hline chloroform & 2.268 & 2.049 & 1.999 \\
\hline chlorobenzene & 2.269 & 2.049 & 1.999 \\
\hline THF & 2.270 & 2.049 & 1.998 \\
\hline methylenechloride & 2.270 & 2.049 & 1.997 \\
\hline quinoline & 2.270 & 2.049 & 1.997 \\
\hline isoquinoline & 2.270 & 2.049 & 1.997 \\
\hline
\end{tabular}

* A. Hameed, A. Rybarczyk-Pirek, J. Zakrzewski, Journal of Organometallic Chemistry, 656 (2002) 102-107.

\section{Frontier orbitals energy}

The influence of solvent nature is reflected not only in the geometric parameters of the molecules, but also in the energies of frontier orbitals. It is well-known that the frontier orbitals energy and HOMO-LUMO gap values are closely related to the optical and electronic properties.

Inclusion of solvation effects leads also to changes on the molecular orbital energies (Table 3). In solution, with respect to the corresponding values in vacuum due to the effect of polarization of the media, frontier orbitals are destabilized.

On the other hand, the HOMO-LUMO gaps in solvated media are higher than in the corresponding values computed in vacuum. A good linear relation is seen between HOMO-LUMO gaps and dielectric constant of solvents $\left(\Delta \mathrm{E}_{\text {номо-цuмо }}=0.006 \varepsilon+1.229\right.$ $\mathrm{R}^{2}=0.965$ ).

As well as, the study of solvent effect on the chemical potential values shows that these values increase with the increasing of polarity of solvent. On the other hand, electrophilicity values decrease with the increasing of polarity of solvent. There is a good correlation between chemical potential and electrophilicity values with dielectric constant of solvents $\left(\mathrm{R}^{2}=0.952\right.$ and 0.956 , respectively).
Table 3. Frontier orbital energies (a.u), HOMO-LUMO gap $(\Delta \mathrm{E}, \mathrm{eV})$, hardness $(\eta \mathrm{eV})$, chemical potential $(\mu, \mathrm{eV})$, electrophilicity $(\omega, \mathrm{eV})$ for $\mathrm{W}(\mathrm{CO})_{5} \mathrm{~L}, \mathrm{~L}=(4$-pyridylmethylene)malononitrile in vacuum and various solvents.

\begin{tabular}{|c|c|c|c|c|c|c|}
\hline & $\begin{array}{c}\mathbf{E} \\
\text { (HOMO) }\end{array}$ & $\begin{array}{c}\mathbf{E} \\
\text { (LUMO) }\end{array}$ & $\Delta \mathbf{E}$ & $\eta$ & $\mu$ & $\omega$ \\
\hline Gas & -0.21928 & -0.17740 & 1.14 & 0.57 & -5.40 & 25.56 \\
\hline chloroform & -0.20632 & -0.16016 & 1.26 & 0.63 & -4.99 & 19.79 \\
\hline chlorobenzene & -0.20589 & -0.15933 & 1.27 & 0.63 & -4.97 & 19.49 \\
\hline THF & -0.20539 & -0.15835 & 1.28 & 0.64 & -4.95 & 19.13 \\
\hline methylenechloride & -0.20514 & -0.15779 & 1.29 & 0.64 & -4.94 & 18.92 \\
\hline quinoline & -0.20511 & -0.15772 & 1.29 & 0.64 & -4.94 & 18.90 \\
\hline isoquinoline & -0.20489 & -0.15725 & 1.30 & 0.65 & -4.93 & 18.73 \\
\hline
\end{tabular}

To get insight into the influence of the optical and electronic properties, the plots of the frontier orbitals for these molecules are investigated, and their sketches are presented in Figure 3. Molecular orbital analysis show that HOMO and LUMO are of the $\pi$ characteristics as visualized in Figure 3. Frontier orbital analysis presents the frontier orbitals are included on the all atoms of molecule.

In addition, the total density of states (DOS), and overlap population density of state (OPDOS) of title complex have been presented in Figure 3 to observe the varieties of the HOMOs, LUMOs, and energy gaps more easily and vividly. These spectra provide graphical representation of $\mathrm{MO}$ compositions and their contributions to chemical bonding. The OPDOS spectra can help us to analyze the bonding (positive value), antibonding (negative value), and nonbonding (near zero value) characters with respect to the particular fragments.

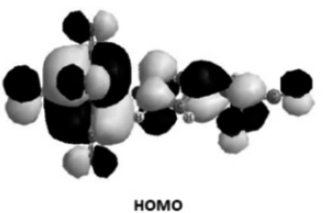

номо

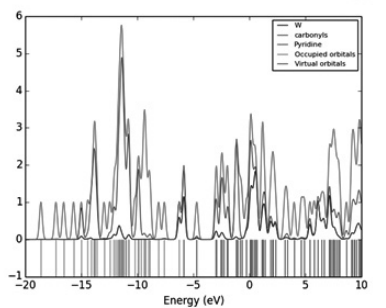

(b)

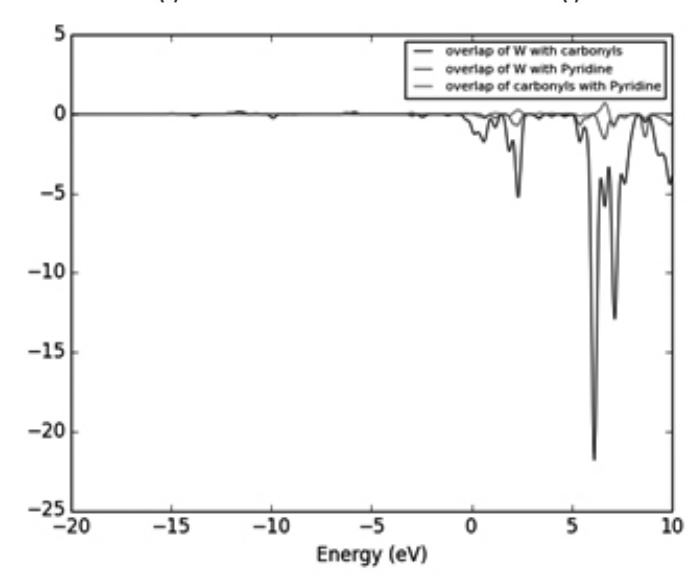

(d)

(c)
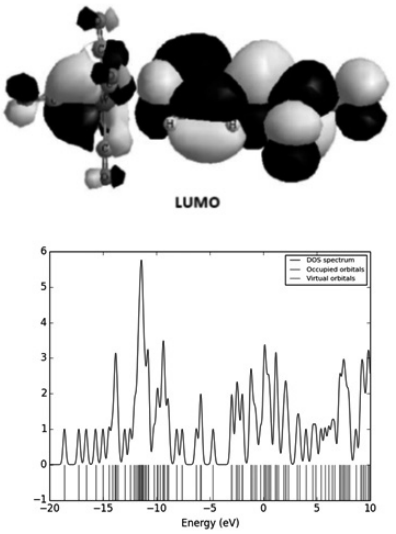

Figure 3. (a) plots of frontier orbitals, (b) Density of states (DOS) spectrum, (c) partial density of states (PDOS)and (d) overlap population density of states (OPDS) plot of $\mathrm{W}(\mathrm{CO}) 5 \mathrm{~L}, \mathrm{~L}=(4$-pyridylmethylene)malononitrile complex. 
7. Vibrational analysis

The stretching frequencies of carbonyl and cyanide in the studied $\mathrm{W}(\mathrm{CO})_{5}$-pyridine- $\pi$-acceptor complex are gathered in Table 4 . The scheme of these vibrations is presented in Figure 4. The comparison of carbonyl stretching frequencies in vacuum and solution phases shows more value in vacuum phase. On the other hand, the cyanide stretching frequencies increase in solution phase rather than gas phase. There is a good correlation between experimental values and theoretical values. The correlation coefficients of the dependency of the frequencies with dielectric constants are: $0.958,0.966,0.952$, and 0.947, for $v_{1}, v_{2}, v_{3}$, and $v_{4}$, respectively.

Table 4. The stretching frequencies of carbonyl and cyanide (in $\mathrm{cm}^{-1}$ ) in studied $\mathrm{W}(\mathrm{CO})_{5} \mathrm{~L}, \mathrm{~L}=(4$-pyridylmethylene)malononitrile complex in vacuum and various solvents.

\begin{tabular}{|c|c|c|c|c|c|}
\hline & $v_{\mathbf{4}}(\mathbf{C} \equiv \mathbf{O})$ & $v_{3}(\mathbf{C} \equiv \mathbf{O})$ & $v_{\mathbf{2}}(\mathbf{C} \equiv \mathbf{O})$ & $v_{\mathbf{1}}(\mathbf{C} \equiv \mathbf{O})$ & $v(\mathbf{C} \equiv \mathbf{N})$ \\
\hline Exp (in $\left.\mathbf{C H C l}_{3}\right)^{*}$ & 2074.0 & 1975.0 & & 1926.0 & 2229.0 \\
\hline Gas & 2060.9 & 1962.5 & 1957.5 & 1956.9 & 2247.3 \\
\hline chloroform & 2058.2 & 1935.0 & 1933.0 & 1931.3 & 2251.0 \\
\hline chlorobenzene & 2057.7 & 1932.4 & 1930.4 & 1927.8 & 2251.0 \\
\hline THF & 2057.2 & 1929.0 & 1927.6 & 1923.8 & 2251.0 \\
\hline methylenechloride & 2056.9 & 1927.4 & 1925.5 & 1921.3 & 2251.0 \\
\hline quinoline & 2056.9 & 1927.2 & 1925.2 & 1921.1 & 2250.9 \\
\hline isoquinoline & 2056.6 & 1925.6 & 1923.6 & 1919.1 & 2251.0 \\
\hline
\end{tabular}

* A. Hameed, A. Rybarczyk-Pirek, J. Zakrzewski, Journal of Organometallic Chemistry, 2002, 656, 102.

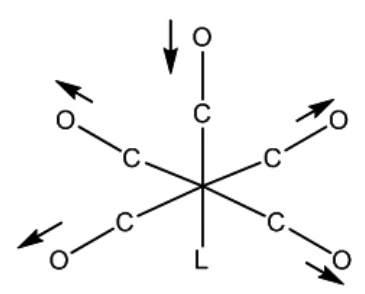

$\mathbf{v}_{1}$

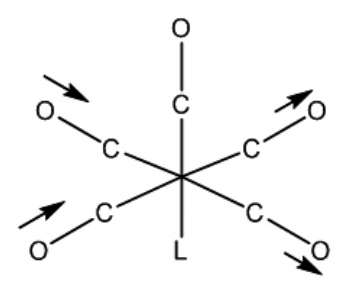

$\mathbf{v}_{2}$



$\mathbf{v}_{3}$



$\mathbf{v}_{4}$

Figure 4. The stretching modes of carbonyl and cyanide $\mathrm{W}(\mathrm{CO}) 5 \mathrm{~L}, \mathrm{~L}=(4-$ pyridylmethylene)malononitrile complex.

\section{Thermodynamic properties}

Based on the vibrational analysis of our title molecule, the thermodynamic parameters such as Heat capacity $\left(\mathrm{C}_{\mathrm{y}}\right)$, entropy $(\mathrm{S})$ and enthalpy $(\mathrm{H})$ were calculated and are listed in Table 5. It can be seen that, when the temperature increases from 100 to $1000 \mathrm{~K}$ the thermodynamic functions $(\mathrm{C}$, $\mathrm{S}$, $\mathrm{H})$ increases, because molecular vibrational intensities increase with temperature [57]. Fitting factor $\left(\mathrm{R}^{2}\right)$ of the thermodynamic functions such as free energy, heat capacity, entropy and enthalpy changes are $0.999,0.999,0.995$ and 0.999 respectively. The quadratic equations of temperature dependence of thermodynamic functions are:

$$
\begin{aligned}
& \mathrm{G}=-2 \times 10^{-7} \mathrm{~T}^{2}-0.000 \mathrm{~T}-1143.0 ; \mathrm{R}^{2}=0.999 \\
& \mathrm{H}=8 \times 10^{-8} \mathrm{~T}^{2}+9 \times 10^{-5} \mathrm{~T}-1143.0 ; \mathrm{R}^{2}=0.999 \\
& \mathrm{C}_{\mathrm{v}}=-0.000 \mathrm{~T}^{2}+0.225 \mathrm{~T}+22.10 ; \mathrm{R}^{2}=0.995 \\
& \mathrm{~S}=0.000 \mathrm{~T}^{2}+0.358 \mathrm{~T}+79.60 ; \mathrm{R}^{2}=0.999
\end{aligned}
$$

Table 5. The calculated thermodynamic parameters of $\mathrm{W}(\mathrm{CO})_{5} \mathrm{~L}, \mathrm{~L}=(4$-pyridylmethylene $)$ malononitrile in vacuum and various temperatures.

\begin{tabular}{|c|c|c|c|c|}
\hline $\mathbf{T}(\mathbf{K})$ & $\mathbf{G}($ Hartree $)$ & $\mathbf{H}($ Hartree $)$ & $\mathbf{C}_{\mathbf{v}}(\mathbf{c a l} / \mathbf{m o l}-\mathbf{K})$ & $\mathbf{S}(\mathbf{c a l} / \mathbf{m o l} . \mathbf{K})$ \\
\hline $\mathbf{1 0 0}$ & -1143.716557 & -1143.716557 & 40.540 & 111.183 \\
\hline $\mathbf{2 0 0}$ & -1143.707909 & -1143.707909 & 63.685 & 147.870 \\
\hline $\mathbf{3 0 0}$ & -1143.695899 & -1143.695899 & 82.154 & 178.174 \\
\hline $\mathbf{4 0 0}$ & -1143.681338 & -1143.681338 & 95.986 & 204.366 \\
\hline $\mathbf{5 0 0}$ & -1143.664842 & -1143.664842 & 106.624 & 227.420 \\
\hline $\mathbf{6 0 0}$ & -1143.646841 & -1143.646841 & 115.002 & 247.992 \\
\hline $\mathbf{7 0 0}$ & -1143.627643 & -1143.627643 & 121.723 & 266.549 \\
\hline $\mathbf{8 0 0}$ & -1143.607478 & -1143.607478 & 127.193 & 283.438 \\
\hline $\mathbf{9 0 0}$ & -1143.586522 & -1143.586522 & 131.693 & 298.921 \\
\hline $\mathbf{1 0 0 0}$ & -1143.564912 & -1143.564912 & 135.428 & 313.205 \\
\hline
\end{tabular}




\section{9. $\quad{ }^{1} \mathrm{H}$ and ${ }^{13} \mathrm{C}$ NMR chemical shifts}

The theoretical and experimental ${ }^{1} \mathrm{H}$ and ${ }^{13} \mathrm{C}$ NMR chemical shifts of the title compound are given in Table 6 . Relative chemical shifts were estimated by using the corresponding TMS shielding calculated in advance at the same theoretical level as the reference.

The studied molecule has two hydrogen atoms in the pyridine ring and a hydrogen atom attached to $\mathrm{C} 4$. The proton signals were observed at 8.34 and $7.23 \mathrm{ppm}$ for ring hydrogen atoms in gas phase. In solution phase, these values are 8.39-840, 7.42-746, and 7.30-7.39, $\mathrm{H} 1, \mathrm{H} 2$, and $\mathrm{H} 4$, respectively. The chemical shift of proton numbered $\mathrm{H} 1$ and $\mathrm{H} 2$ are higher than $\mathrm{H} 4$ atom. It means that the electronic charge densities around the $\mathrm{H} 1$ and $\mathrm{H} 2$ are lower than $\mathrm{H} 4$.

Table 6. ${ }^{1} \mathrm{H}$ and ${ }^{13} \mathrm{C}$ NMR chemical shifts (ppm) for $\mathrm{W}(\mathrm{CO})_{5} \mathrm{~L}, \mathrm{~L}=(4$-pyridylmethylene)malononitrile complex in vacuum and various solvents ${ }^{1} \mathrm{H}$ NMR

\begin{tabular}{|c|c|c|c|}
\hline & H1 & H2 & H4 \\
\hline Exp (in $\mathrm{CHCl}_{3}$ )* & 9.08 & 7.65 & 7.77 \\
\hline Gas & 8.33655 & 7.23035 & 6.9141 \\
\hline chloroform & 8.39435 & 7.41775 & 7.2962 \\
\hline chlorobenzene & 8.39755 & 7.43055 & 7.3239 \\
\hline THF & 8.4004 & 7.4466 & 7.3571 \\
\hline methylenechloride & 8.40305 & 7.45355 & 7.375 \\
\hline quinoline & 8.40325 & 7.45465 & 7.3774 \\
\hline isoquinoline & 8.4039 & 7.4604 & 7.392 \\
\hline
\end{tabular}

${ }^{13} \mathrm{C}$ NMR

\begin{tabular}{|c|c|c|c|c|c|c|c|c|c|c|}
\hline & $\mathbf{C}_{\text {trans }}$ & $\mathbf{C}_{\text {cis }}$ & $\mathbf{C 1}$ & $\mathbf{C 2}$ & $\mathbf{C 3}$ & $\mathbf{C 4}$ & $\mathbf{C 5}$ & $\mathbf{C N}$ & $\mathbf{C N}$ & $\mathbf{R}^{\mathbf{2}}$ \\
\hline Exp (in CHCl ) $^{*}$ & 201.9 & 198.3 & 157.4 & 124.3 & 137.8 & 151.3 & - & 112.0 & 111.0 & - \\
\hline Gas & 206.82 & 193.11 & 153.37 & 118.83 & 134.16 & 150.39 & 84.27 & 112.33 & 112.31 & 0.989 \\
\hline chloroform & 207.75 & 193.79 & 154.26 & 121.16 & 135.16 & 155.80 & 82.96 & 113.58 & 114.16 & 0.987 \\
\hline chlorobenzene & 207.84 & 193.84 & 154.33 & 121.34 & 135.24 & 156.20 & 82.87 & 113.68 & 114.31 & 0.987 \\
\hline THF & 207.94 & 193.89 & 154.42 & 121.54 & 135.33 & 156.68 & 82.76 & 113.81 & 114.47 & 0.986 \\
\hline methylenechloride & 208.01 & 193.95 & 154.46 & 121.67 & 135.39 & 156.95 & 82.70 & 113.87 & 114.58 & 0.986 \\
\hline quinoline & 208.01 & 193.95 & 154.46 & 121.68 & 135.40 & 156.99 & 82.70 & 113.88 & 114.59 & 0.986 \\
\hline isoquinoline & 208.06 & 193.98 & 154.49 & 121.78 & 135.44 & 157.21 & 82.64 & 113.94 & 114.67 & 0.986 \\
\hline
\end{tabular}

* A. Hameed, A. Rybarczyk-Pirek, J. Zakrzewski, Journal of Organometallic Chemistry, 2002, 656, 102.

9. Hyperpolarizability

It is illustrated that solvent polarity participates an important role on the first hyperpolarizabilities in dipolar molecules.

The $\beta$, values of $\mathrm{W}(\mathrm{CO})_{5}$-pyridine- $\pi$-acceptor complex in the various solvents have been gathered in Table 7 . These values indicate that $\beta_{\text {tot }}$ values increase from vacuum to solution phase. The dependence of the first
The signals of carbonyl carbon atoms were observed at 206.82 and 137.69 ppm for $\mathrm{C}_{\text {trans }}$ and $\mathrm{C}_{\text {cis }}$, respectively, in gas phase. These atoms have larger chemical shifts than the other ring carbon atoms because of electronegativity of oxygen atoms.

The signals of aromatic carbon atoms were observed at 153.37, 118.83 and $4.16 \mathrm{ppm}$, respectively, in gas phase. $\mathrm{C} 1$ atom has larger chemical shift than the other ring carbon atoms because of electronegativity of nitrogen atoms.

The relations between the experimental and calculated chemical shifts are investigated in gas and solution phases and correlation coefficients are gathered in Table 6.

Table 7. All $\beta$ components and $\beta_{\text {tot }}$ value calculated for $\mathrm{W}(\mathrm{CO})_{5} \mathrm{~L}, \mathrm{~L}=(4$-pyridylmethylene)malononitrile complex in vacuum and various solvents.

\begin{tabular}{|c|c|c|c|c|c|c|c|}
\hline & gas & Chloroform & chlorobenzene & THF & methylenechloride & quinoline & isoquinoline \\
\hline $\boldsymbol{\beta}_{\mathbf{X X X}}$ & -28264.43 & -80183.91 & -84731.12 & -90174.71 & -93187.75 & -93594.46 & -96145.53 \\
\hline $\boldsymbol{\beta}_{\mathbf{X X Y}}$ & -1170.35 & -3310.52 & -3516.30 & -3774.66 & -3909.82 & -3921.12 & -4044.76 \\
\hline $\boldsymbol{\beta}_{\mathbf{X Y Y}}$ & 49.87 & 61.99 & 49.70 & 38.59 & 48.05 & 46.82 & 43.80 \\
\hline $\boldsymbol{\beta}_{\mathbf{Y Y Y}}$ & -86.43 & -133.16 & -103.03 & -133.26 & -131.09 & -132.22 & -129.30 \\
\hline $\boldsymbol{\beta}_{\mathbf{X X Z}}$ & -12.58 & -23.53 & -23.22 & -14.42 & -35.78 & -31.27 & -36.67 \\
\hline $\boldsymbol{\beta}_{\mathbf{X Y Z}}$ & -1.63 & 9.92 & 2.38 & 6.18 & 9.38 & 10.12 & 9.45 \\
\hline $\boldsymbol{\beta}_{\mathbf{Y Y Z}}$ & -1.99 & 9.55 & 3.27 & 0.48 & 5.77 & 5.99 & 4.44 \\
\hline $\boldsymbol{\beta}_{\mathbf{X Z Z}}$ & 203.61 & 407.40 & 417.46 & 441.72 & 449.64 & 449.82 & 459.41 \\
\hline $\boldsymbol{\beta}_{\mathbf{Y Z Z}}$ & -4.87 & -19.86 & -16.61 & -20.61 & -20.58 & -20.90 & -19.93 \\
\hline $\boldsymbol{\beta}_{\mathbf{Z Z Z}}$ & -0.82 & 7.44 & 26.55 & 4.95 & 11.85 & 11.64 & 12.35 \\
\hline$\beta_{\text {tot }}$ & $2.42 \mathrm{E}-28$ & $6.89 \mathrm{E}-28$ & $7.29 \mathrm{E}-28$ & $7.76 \mathrm{E}-28$ & $8.01 \mathrm{E}-28$ & $8.05 \mathrm{E}-28$ & $8.27 \mathrm{E}-28$ \\
\hline$\beta_{\mathrm{tot}}\left(\times \mathbf{1 0}^{-30}\right)$ & 242.25 & 689.37 & 728.70 & 775.68 & 801.59 & 805.12 & 827.12 \\
\hline
\end{tabular}


Table 8. The second-order perturbation energies E(2) (kcal/mol) corresponding to the most important charge transfer interactions (donor $\rightarrow$ acceptor) for $\mathrm{W}(\mathrm{CO})_{5} \mathrm{~L}, \mathrm{~L}=(4$-pyridylmethylene)malononitrile complex.

\begin{tabular}{|c|c|c|c|}
\hline Donor NBO $\rightarrow$ acceptor NBO & $\mathbf{E ( 2 )}$ & $\mathbf{E ( j ) - E ( i )}$ & $\mathbf{F ( i , j )}$ \\
\hline $\mathrm{LP}(2) \mathrm{O}_{\text {trans }} \rightarrow \mathrm{BD}^{*}(2) \mathrm{W}_{-} \mathrm{C}_{\text {trans }}$ & 114.59 & 0.24 & 0.149 \\
\hline $\mathrm{BD}(2) \mathrm{C} 2-\mathrm{C} 3 \rightarrow \mathrm{LP}(2) \mathrm{N}_{\mathrm{py}}$ & 100.77 & 0.03 & 0.071 \\
\hline $\mathrm{BD}(2) \mathrm{C} 1-\mathrm{C} 2 \rightarrow \mathrm{LP}(2) \mathrm{N}_{\mathrm{py}}$ & 94.06 & 0.04 & 0.072 \\
\hline $\mathrm{LP}(1) \mathrm{N}_{\mathrm{py}} \rightarrow \mathrm{LP} *(3) \mathrm{W}$ & 96.41 & 0.52 & 0.206 \\
\hline
\end{tabular}

Table 9. The NQR parameters calculated and principal components of the EFG tensors for the nitrogen, for W(CO) $\mathrm{L}, \mathrm{L}=(4-\mathrm{pyridylmethylene})$ malononitrile complex in vacuum and various solvents. $\mathrm{R}^{2}$ is correlation coefficients of NQR parameters and dielectric constants.

\begin{tabular}{|c|c|c|c|c|c|c|c|c|c|c|}
\hline molecule & $q_{x x}($ a.u) & $\mathbf{q}_{y y}$ (a.u) & $\mathrm{q}_{z z}$ (a.u) & $\left(e^{2} \mathbf{Q} / h\right) q_{x x}$ & $\left(\mathrm{e}^{2} \mathbf{Q} / \mathbf{h}\right) \mathbf{q}_{\mathrm{yy}}$ & $\left(\mathrm{e}^{2} \mathbf{Q} / \mathrm{h}\right) \mathrm{q}_{z z}$ & $\eta$ & $v_{+}$ & $v_{-}$ & $\mathrm{v}_{0}$ \\
\hline Gas & -0.2428 & -0.3558 & 0.5987 & -1.166 & -1.709 & 2.875 & 0.189 & 2.292 & 2.021 & 0.271 \\
\hline chloroform & -0.2344 & -0.3589 & 0.5932 & -1.126 & -1.724 & 2.849 & 0.2099 & 2.286 & 1.987 & 0.299 \\
\hline THF & -0.2333 & -0.3585 & 0.5919 & -1.121 & -1.722 & 2.843 & 0.2115 & 2.282 & 1.982 & 0.301 \\
\hline methylenechloride & -0.2330 & -0.3583 & 0.5913 & -1.119 & -1.721 & 2.840 & 0.2120 & 2.281 & 1.979 & 0.301 \\
\hline $\mathbf{R}^{2}$ & 0.957 & 0.990 & 0.971 & 0.927 & 0.988 & 0.971 & 0.934 & 0.968 & 0.953 & 0.723 \\
\hline
\end{tabular}

10. Natural bond orbital analysis (NBO)

According to the NBO results, the electron configuration of $\mathrm{W}$ is [core]6 $\mathrm{S}(0.46) 5 \mathrm{~d}(6.09) 6 \mathrm{p}(1.02) 6 \mathrm{~d}(0.02)$ in title complex. Thus there exist only 7.58 valence electrons. This is consistent with the calculated natural charge on $\mathrm{W}$ atom $(-1.55)$ which corresponds to the difference between $7.58 \mathrm{e}$ and the total number of valence electrons in the isolated $\mathrm{W}$ atom.

The stabilization energy $\mathrm{E}(2)$ is estimated by second order perturbation theory in terms of NBO analysis.

Figure 5 depicts the natural charges on atoms. The largest negative charge is located on W.

The most important interaction between "filled" (donor) Lewis type NBOs and "empty" (acceptor) non-Lewis NBOs is reported in Table 8. This shows that the most charge transfer energy is for LP (2) $\mathrm{O}_{\text {trans }} \rightarrow \mathrm{BD} *(2) \mathrm{W}-\mathrm{C}$ t

Also, NBO analysis indicates $\mathrm{W}$ atom forms bond with carbon atoms. NBO analysis shows that, the $\sigma(\mathrm{W}-\mathrm{C})$ bond is formed from a sp ${ }^{\mathrm{m}} \mathrm{d}^{\mathrm{n}}$ hybric on W. On the other hand, $\pi(\mathrm{W}-\mathrm{C})$ bond is formed from a $\mathrm{p}^{\mathrm{m}} \mathrm{d}^{\mathrm{n}}$ hybrid on $\mathrm{W}$ :

$\sigma\left(\mathrm{W}-\mathrm{C}_{\mathrm{ci}}\right): 0.5503\left(\mathrm{sp}^{3.25} \mathrm{~d}^{2.28}\right)_{\mathrm{W}}+0.8350\left(\mathrm{sp}^{0.47}\right){ }_{\mathrm{C}(\mathrm{cis})}$

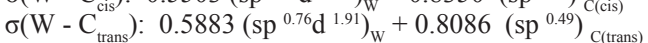
$\pi\left(\mathrm{W}-\mathrm{C}_{\text {trans }}\right): 0.8924\left(\mathrm{p}^{1.00} \mathrm{~d}^{99.99}\right)_{\mathrm{W}}+0.4512\left(\mathrm{p}^{1.00}\right)_{\mathrm{C} \text { (trans) }}$

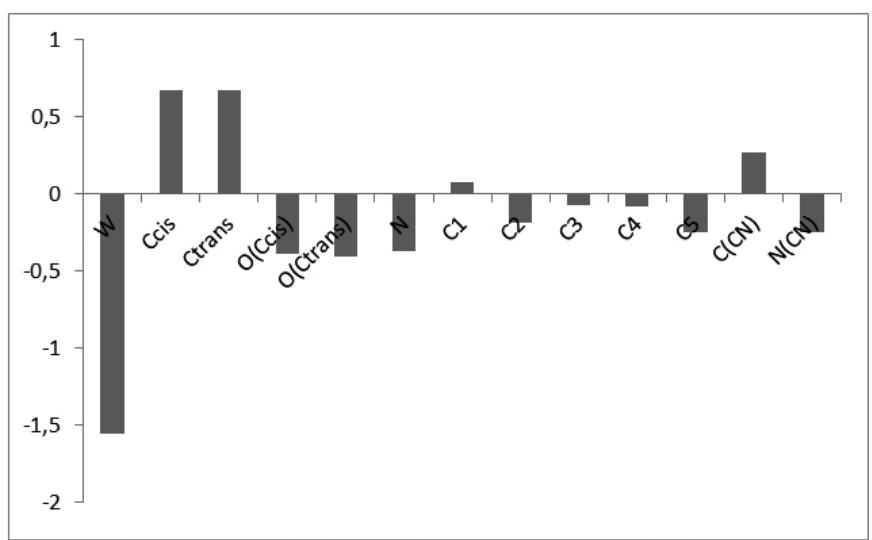

Figure 5. The molecular charge distribution on the skeletal atoms for studied complexes.
Table 10. Maximum Absorption wavelength $(\lambda, \mathrm{nm})$, and Oscillator strength (f) for $\mathrm{W}(\mathrm{CO})_{5} \mathrm{~L}, \mathrm{~L}=(4$-pyridylmethylene)malononitrile complex.

\begin{tabular}{|c|c|c|c|}
\hline & attributed & $\lambda_{\max }$ & f \\
\hline chloroform & HOMO -> LUMO+5 & 342.97 & 0.2573 \\
\hline chlorobenzene & HOMO -> LUMO+5 & 342.53 & 0.2696 \\
\hline THF & HOMO -> LUMO+5 & 341.20 & 0.2797 \\
\hline methylenechloride & HOMO -> LUMO+5 & 340.75 & 0.2942 \\
\hline quinoline & HOMO - LUMO+5 & 337.99 & 0.2073 \\
\hline isoquinoline & HOMO -> LUMO+5 & 337.47 & 0.2136 \\
\hline
\end{tabular}

Table 11. Electron densities $\rho\left(\mathrm{e} / \mathrm{a}_{0}{ }^{3}\right)$, Laplacians $\nabla^{2} \rho\left(\mathrm{e} / \mathrm{a}_{0}{ }^{5}\right)$, total electron energy density, $H(\rho)$, kinetic energy density, $G(\rho)$, and potential energy density, $\mathrm{V}(\rho)$ at the W-C and W-N critical points for $\mathrm{W}(\mathrm{CO})_{5} \mathrm{~L}, \mathrm{~L}=(4-$ pyridylmethylene $)$ malononitrile complex.

\begin{tabular}{|c|c|c|c|c|c|}
\hline & $\rho$ & $\nabla^{2} \rho$ & G & H & V \\
\hline $\mathrm{W}-\mathrm{CO}_{\text {tran }}$ & 0.11868 & 0.42736 & 0.14336 & -0.03652 & -0.17987 \\
\hline $\mathrm{W}-\mathrm{COc}_{\text {is }}$ & 0.10647 & 0.40514 & 0.12970 & -0.02842 & -0.15812 \\
\hline W-N & 0.06699 & 0.28925 & 0.07895 & -0.00663 & -0.08558 \\
\hline
\end{tabular}

\section{1. ${ }^{14} \mathrm{~N}-\mathrm{NQR}$ parameters}

The distortion of the charge distributions around the nitrogen atom has been investigated, and interpreted by EFGs. Since the EFG around a nitrogen nucleus is symmetric in $\mathrm{N}_{2}$ free molecule, the calculated values of NQR parameters for $\mathrm{N}_{2}$ molecule are $\eta_{\mathrm{e}}=0$ and $v^{\text {cal }}=4.258 \mathrm{MHz}$. The calculated $\mathrm{NQR}$ frequencies of nitrogen atom of pyridine in the studied $\mathrm{W}(\mathrm{CO})_{5}$-pyridine$\pi$-acceptor complex in gas phase and different solvents are listed in Table 9. As shown in Table 9, the magnitude of the $\chi_{z z}$ decreases and $\eta$ values increase in the solution phase rather than in the vacuum phase. On the other hand, $v, v$, and $v_{0}$ frequencies are dependent on polarity of the solvents. Table 9 represents correlation coefficients of linear relationships between ${ }^{14} \mathrm{NQR}$ parameters values and dielectric constants.

\section{Electronic spectra}

We found the most intense electronic transition $\left(\lambda_{\max }\right)$ of molecules in different solvents. The wavelength, oscillator strength and the composition of the transitions obtained by TD-DFT calculations are given in Table 10 . Theoretical calculations indicate that, $\mathrm{HOMO} \rightarrow \mathrm{LUMO}+5$ transition in title molecule makes the major contribution in this electronic transition. On the other hand, inclusion of solvent leads to changing of $\lambda_{\max }$ values. The $\lambda_{\max }$ 
values decrease with increasing of polarity of solvent.

\section{AIM analysis}

It has been proved that the AIM-based analysis of electron density can provide valuable information on many physical and chemical properties of molecular systems [62-66].

Table 11 indicates that $\nabla^{2} \rho$ values of $\mathrm{W}-\mathrm{C}_{\text {cis }}, \mathrm{W}_{-} \mathrm{C}_{\text {trans }}$, and $\mathrm{W}-\mathrm{N}$ bonds at corresponding BCPs are positive, as it was found for closed-shell interactions. On the other hand, the $\mathrm{H}(\rho)$ values are negative, as found for shared interactions. This is in agreement with observations made for the $\mathrm{Ti}-\mathrm{C}$ bonds in titanium complexes [67] and transition metal carbonyl clusters [68], in the case when the metal-ligand bonding has a characteristic that represents a mix of the closed-shell and shared parameters. The strong polar character is also revealed by the large $\mathrm{G}(\mathrm{rb}) / \rho(\mathrm{rb})$ ratio and atomic charges, while the covalence is manifested by large and negative $\mathrm{H}(\mathrm{rb}) / \rho(\mathrm{rb})$ (Table 11).

Moreover, the $\mathrm{H}(\rho)$ values are more negative for $\mathrm{W}-\mathrm{C}_{\text {cis }}$ and $\mathrm{W}-\mathrm{C}_{\text {trans }}$, which is directly connected with greater relative predominance of $V(\rho)$ magnitude over the $G(\rho)$ magnitude. This suggests a more covalent character of the $\mathrm{W}-\mathrm{C}_{\mathrm{cis}}$ and $\mathrm{W}-\mathrm{C}_{\mathrm{trans}}$ bonds. Furthermore, $\mathrm{W}-\mathrm{C}_{\mathrm{cis}}$ and $\mathrm{W}-\mathrm{C}_{\text {trans }}$ bonds have more negative $H(\rho)$ values rather than $\mathrm{W}-\mathrm{N}$ bond. Generally, when the value of $|\mathrm{H}(\rho)|$ are greater (with negative sign), there is more covalent character of the bond.

\section{CONCLUSION}

In this paper, the structural and spectroscopic properties of $\mathrm{W}(\mathrm{CO})_{5} \mathrm{~L}$, $\mathrm{L}=(4$-pyridylmethylene)malononitrile complex were studied by means of PBEPBE method which indicated:

1. $\mathrm{E}_{\text {solv }}$ values indicate the increasing of stability of title complex in more polar solvents.

2. Molecular orbital analysis shows that HOMO and LUMO are of the $\pi$ characteristics, and they are distributed on all atoms of the molecule.

3. The hyperpolarzability values increase from vacuum to solution phase, and are dependent on the dielectric constant of the media and the Onsager function.

4. The ${ }^{14} \mathrm{~N}$ NQR parameters show that the magnitude of the $\chi_{2 z}$ decreases and $\eta$ values increase in the solution phase rather than in the vacuum phase.

5. AIM analysis shows that $\mathrm{W}-\mathrm{C}$ bonds have more covalent characters than W-N bond.

6. The theoretical chemical shift values of ${ }^{13} \mathrm{C}$ and ${ }^{1} \mathrm{H}$ NMR spectra are compatible with experimental results.

\section{REFERENCES}

1. I. A. Morkan,A. U. Morkan, Spectrochimica Acta Part A 2011, 79, 1715.

2. K. A. Rawlins, A. J. Lees, A. W. Adamsod, Inorg. Chem 1990, 29, 3866.

3. E. I. Solomon,P. M. Jones,J. A. May, Chem. Rev 1993, 93, 2623.

4. S. V. Timofeev,O. B. Zhidkova,E. M. Mosolova,I. B. Sivaev,I. A. Godovikov,K. Y. Suponitsky,Z. A. Starikova,V. I. Bregadze, Dalton Transactions 2015, 6449 .

5. S. V. Timofeev,M. V. Zakharova,E. M. Mosolova,I. A. Godovikov,I. V. Ananyev,I. B. Sivaev,V. I. Bregadze, J. Organomet. Chem. 2012, 721$722,92$.

6. A. W. Ehlers,S. Dapprich,S. F. Vyboishchikov,G. Frenking, Organometallics 1996, $15,105$.

7. R. M. Kolodziej,A. J. Lees, Organometallics 1986, 5, 450.

8. Q. Li,R. Sa,C. Liu,K. Wu, J. Phys. Chem. A 2007, 111, 7925.

9. M. Wrighton, G. S. Hammond,H. B. Gray, J. Am. Chem. Soc 1971, 93, 4336.

10. M. Wrighton,G. S. Hammond,H. B. Gray, Inorg. Chem. 1972, 11, 3122.

11. M. Wrighton,G. S. Hammond,H. B. Gray, Mol. Pfiotochem. 1973, 5, 179.

12. M. S. Wrighton,H. B. Abrahamson,D. L. Morse, J. Am. Chem. Soc 1976, 98, 4105 .

13. A. J. Lees,A. W. Adamson, J. Am. Chem. Soc. 1982, 104, 3804.

14. A. J. Lees,A. W. Adamson, J. Am. Chem. Soc. 1980, 102, 6874.

15. D. R. Kanis,M. A. Ratner,T. J. Marks, Chem. Rev 1994, 94, 195

16. D. R. Kanis,P. G. Lacroix,M. A. Ratner,T. J. Marks, J. Am. Chem. Soc $1994,1116,10089$

17. N. J. Long, Angew. Chem. Int. Edit. Engl. 1995, 34, 21.

18. H. L. Bozec, T. Renouard, Eur. J. Inorg. Chem. 2000, 229.

19. S. DiBella, Chem. Soc. Rev. 2001, 30, 355.
20. I. S. Lee,S. S. Lee,Y. K. Chung,D. Kim,N. W. Song, Inorg. Chim. Acta 1998, 279, 243.

21. J. Mata,S. Uriel,E. Peris,R. Llusar,S. Houbrechts,A. Persoons, J. Organomet. Chem. 1998, 562, 197.

22. J. F. Lamere,I. Sasaki,P. G. Lacroix,K. Nakatani, New J. Chem. 2006, 30, 921.

23. M. Pizzotti,R. C. Dragonetti,E. Annoni,F. Demartin,P. Mussin, Organometallics 2003, 22, 4001.

24. A. Hameed,A. Rybarczyk-Pirek,J. Zakrzewski, Journal of Organometallic Chemistry 2002, 656, 102

25. R. Ghiasi, Journal of Theoretical and Computational Chemistry 2015, 14 , 1550022.

26. R. Ghiasi,H. Ghiasi.,M. Afzalitabar, Revue Roumaine de Chimie 2014 $59,749$.

27. A. Peikari,R. Ghiasi,H. Pasdar, Russian Journal of Physical Chemistry A 2015, 89, 250 .

28. M. Z. Fashami,R. Ghiasi,H. Pasdar, Journal of Structural Chemistry 2015, 56, 1474.

29. R.Ghiasi,M. Z. Fashami, Journal of Theoretical and Computational Chemistry 2014, 13, 1450041.

30. R. Ghiasi,E. Amini, Journal of Structural Chemistry 2015, 56, 1483.

31. M. J. Frisch,G. W. Trucks,H. B. Schlegel,G. E. Scuseria,M. A. Robb,J. R. Cheeseman,G. Scalman,V. Barone,B. Mennucci,G. A. Petersson,H. Nakatsuji,M. Caricato,X. Li,H. P. Hratchian,A. F. Izmaylov,J. Bloino,G. Zheng,J. L. Sonnenberg,M. Hada,M. Ehara,K. Toyota,R. Fukuda,J. Hasegawa,M. Ishida,T. Nakajima,Y. Honda,O. Kitao,H. Nakai,T. Vreven,J. A. Montgomery,Jr.,J. E. Peralta,F. Ogliaro,M. Bearpark,J. J. Heyd,E. Brothers,K. N. Kudin,V. N. Staroverov,R. Kobayashi,J. Normand,K. Raghavachari,A. Rendell,J. C. Burant,S. S. Iyengar,J. Tomasi,M. Cossi,N. Rega,J. M. Millam,M. Klene,J. E. Knox,J. B. Cross,V. Bakken,C. Adamo,J. Jaramillo,R. Gomperts,R. E. Stratmann,O. Yazyev,A. J. Austin,R. Cammi,C. Pomelli,J. W. Ochterski,R. L. Martin,K. Morokuma,V. G. Zakrzewski,G. A. Voth,P. Salvador,J. J. Dannenberg,S. Dapprich,A. D. Daniels,O. Farkas,J. B. Foresman,J. V. Ortiz,J. Cioslowski,D. J. Fox: Gaussian 09. Revision A.02 ed.; Gaussian, Inc.: Wallingford CT, 2009.

32. R. Krishnan,J. S. Binkley,R. Seeger,J. A. Pople, J. Chem. Phys. 1980, 72, 650.

33. A. J. H. Wachters, J. Chem. Phys. 1970, 52, 1033

34. P. J. Hay, J. Chem. Phys. 1977, 66, 4377.

35. A. D. McLean, G. S. Chandler, J. Chem. Phys. 1980, 72, 5639.

36. P. J. Hay,W. R. Wadt, J.Chem.Phys 1985, 82, 299.

37. P. J. Hay,W. R. Wadt, J.Chem.Phys 1985, 82, 284.

38. A. Schaefer,H. Horn, R. Ahlrichs, J.Chem.Phys 1992, 97, 2571.

39. J. P. Perdew,K. Burke,M. Ernzerhof, Phys. Rev. Lett. 1996, 77, 3865.

40. J. Tomasi,B. Mennucci,R. Cammi, Chem. Rev. 2005, 105, 2999-

41. A. E. Reed,L. A. Curtiss,F. Weinhold, Chem. Rev. 1988, 88, 899.

42. E. D. Glendening,A. E. Reed,J. E. Carpenter,F. Weinhold: NBO. 3.1. ed.; Gaussian Inc: Pittsburg, PA, 2003.

43. N. M. O’Boyle,A. L. Tenderholt,K. M. Langner, J. Comp. Chem. 2008 , 29,839 .

44. R. F. W. Bader: AIM2000 Program. 2.0 ed.: Hamilton, McMaster University, 2000.

45. D. A. Keleiman, Phy. Rev. 1962, 126, 1977.

46. J. D. Graybeal: Molecular Spectroscopy; McGraw-Hill, 1988.

47. J. Seliger: Nuclear Quadrupole Resonance, Theory - Encyclopedia of Spectroscopy and Spectrometry; Academic Press, 2000.

48. C. P. Slichter: Principles of Magnetic Resonance; Third ed.; SpringerVerlag: Heidelberg, 1990.

49. M. Tokman,D. Sundholm,P. Pyykkö,J. Olsen, Chem. Phys. Lett. 1997, 265,60 .

50. K. Wolinski,J. F. Hinton,P. Pulay, J. Am. Chem. Soc. 1990, 112, 8251.

51. A. Curioni,M. Boero,W. Andreoni, Chem Phys Lett 1998, $294,263$.

52. I. Wang,E. Botzung-Appert,O. S. p. O,A. Ibanez,P. L. Baldeck, J Opt A Pure Appl Opt 2002, 4, S258.

53. P. J. Mendes,T. J. L. Silva,A. J. P. Carvalho,J. P. P. Ramalho, Journal of Molecular Structure: THEOCHEM 2010, 946, 33.

54. L. M. Chen,J. C. Chen,H. Luo,e. al., Journal of Theoretical and Computational Chemistry 2011, 10, 581.

55. X. Cao,C. Liu,Y. Liu, Journal of Theoretical and Computational Chemistry 2012, 11, 573.

56. C. W. Landorf,M. M. Haley, Angew. Chem. Int. Ed. 2006, 45, 3914. 
57. J. B. Ott,J. Boerio-Goates: Chemical Thermodynamics: Advanced Applications, Calculations from Statistical Thermodynamics; Academic Press, 2000.

58. L. Onsager, J. Am. Chem. Soc. 1936, 58, 1486.

59. K. Clays,A. Persoons, Phys. Rev. Lett. 1991, 66, 2980.

60. H. Lee,S.-Y. An,M. Cho, J. Phys. Chem. B 1999, 103, 4992.

61. P. C. Ray,J. Leszczynski, Chem. Phys. Lett. 2004, 399, 162.

62. L. Sobczyk,S. J. Grabowski,T. M. Krygowski, Chem. Rev. 2005, 105 3513.
63. R. F. W. Bader,C. F. Matta,F. Corte's-Guzman, Organometallics 2004, 23, 6253.

64. X. Fradera,M. A. Austen,R. F. W. Bader, J. Phys. Chem. A 1999, 103304.

65. R. F. W. Bader,D.-F. Fang, J. Chem. Theor. Comput. 2005, 1, 403.

66. P. M. Mitrasinovic, Can. J. Chem. 2003, $81,542$.

67. M. Palusiak, J. Organometallic. Chem 2005, 692, 3866

68. P. Macchi,A. Sironi, 2003, 239, 383. 